RAP CONFERENCE PRoceEdINGS, VOL. 5, PP. 3-6, 2020

ISSN 2737-9973 (ONLINE) | DOI: 10.37392/RAPPROC.2020.02

RAP-PROCEEDINGS.ORG

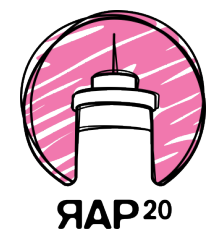

\title{
STRUCTURAL PROPERTIES AND RADIATION RESPONSE OF NEODYMIUM OXIDE
}

\author{
Ramazan Lok', Erhan Budak, ${ }^{1,2}$ Ercan Yilmaz ${ }^{1,3^{*}}$ \\ ${ }^{1}$ Nuclear Radiation Detector Research and Applications Center, Bolu Abant Izzet Baysal University, Bolu, Turkey \\ 2Department of Chemistry, Faculty of Art and Science, Bolu Abant Izzet Baysal University, Bolu, Turkey \\ 3Department of Physics, Faculty of Art and Science, Bolu Abant Izzet Baysal University, Bolu, Turkey
}

\begin{abstract}
Neodymium oxide $\left(\mathrm{Nd}_{2} \mathrm{O}_{3}\right)$ was deposited by the sol-gel method on a P-type $\langle 100\rangle$ silicon wafer. The chemical characterization of neodymium oxide was performed by Fourier transform infrared spectroscopy (FTIR), $X$-ray diffraction (XRD), energy-dispersive spectra (EDS), and atomic force microscopy (AFM), and surface morphology was examined by the scanning electron microscopy (SEM). In order to examine the neodymium oxide radiation response, samples were irradiated using a Co-6o gamma-ray source from 1 to 100 Gy at a dose rate of $0.015 \mathrm{~Gy} / \mathrm{s}$. A dramatic variation was observed in the capacitance and conductance with increasing radiation dose. Irradiation creates a large number of e-h pairs and defects in the structure. For this reason, significant changes can occur in the electrical characteristics of the device. Consequently, neodymium oxide may have significant usage for microelectronic technology for radiation sensors.
\end{abstract}

Keywords: $\mathrm{Nd}_{2} \mathrm{O}_{3} \mathrm{MOS}$ capacitors, irradiation response, interface states, oxide trapped charges

\section{INTRODUCTION}

The basic structures of MOSFETs are MOS capacitors. Since MOSFETs are widely used in many areas, MOS capacitors are being studied extensively.

$\mathrm{SiO}_{2}$ is used as an insulator in conventional MOS capacitors. $\mathrm{SiO}_{2}$ is a limiting factor in reducing device size due to the properties of the dielectric material. The thickness of the $\mathrm{SiO}_{2}$ layer decreases with the reduction in dimensions, which causes the dielectric property of $\mathrm{SiO}_{2}$ to be insufficient [1]. In order to overcome these problems, search has been made for new materials that can be used instead of $\mathrm{SiO}_{2}[2,3]$. For this reason, many dielectric materials have been studied extensively in recent years [4-6].

MOS capacitors can be used for radiation measurement systems due to trapping of radiationinduced charges in the dielectric layer. The purpose of this study is to examine the radiation-dependent properties of neodymium oxide dielectric material.

\section{EXPERIMENTAL DETAILS}

$\mathrm{Nd}_{2} \mathrm{O}_{3}$ was deposited on a P-type silicon substrate (100) by the sol-gel dip coating. All reagents were analytically available and were used without further purification. For the sol-gel preparation, $0.1 \mathrm{~g}$ of $\mathrm{NdCl}_{3}$ powder was dissolved in $50 \mathrm{ml}$ of concentrated acetic acid at $50^{\circ} \mathrm{C}$. After dissolving the powder, the temperature of the solution was kept between $60-70^{\circ} \mathrm{C}$ and stirred for two hours. Then, $50 \mathrm{ml}$ of ethylene glycol was added to the solution and mixed at the same temperature for an extra four hours. After 3 days of aging, the silicon wafer was placed into the $\mathrm{NdCl}_{3} / \mathrm{CH}_{3} \mathrm{COOH}$ and then the pre-coated film was annealed in air at $650^{\circ} \mathrm{C}$ for 2 hours.

Types of chemical bonding in $\mathrm{Nd}_{2} \mathrm{O}_{3}$ were determined by a Perkin Elmer Spectrum Two FTIRATR spectrophotometer. Crystallinity of $\mathrm{Nd}_{2} \mathrm{O}_{3}$ was analyzed by a Rigaku Multiflex Diffractometer employing $\mathrm{CuKa}$ radiation, while the cross-section of the films was obtained by a Jeol JSM 6390LV Scanning Electron Microscope. In addition, the energydispersive X-Ray (EDX) was used to determine the average chemical composition of $\mathrm{Nd}_{2} \mathrm{O}_{3}$. For the electrical characterization, back and front aluminium (Al) contacts were done; front side $\mathrm{Al}$ electrodes were formed through a shadow mask in circular dots with a $1.5 \mathrm{~mm}$ diameter by using the sputtering technique.

Neodymium oxide MOS capacitors were irradiated with a ${ }^{60} \mathrm{Co}$ source. After each irradiation step, up to the maximum dose of $200 \mathrm{~Gy}$, the capacitance-voltage $(\mathrm{C}-\mathrm{V})$ measurements were taken.

\section{RESULTS AND DISCUSSION}

The elemental analysis of the $\mathrm{Nd}_{2} \mathrm{O}_{3}$ thin film, EDS, was performed and the results are shown in Figure 1. High proportions of oxygen and neodymium were found in the structure. Neodymium ratio was found to be approximately $59.41 \%$. The oxygen concentration corresponding to neodymium in the building was

\footnotetext{
"yilmaz@ibu.edu.tr
} 
calculated to be approximately $10.21 \%$. The source of the excess oxygen is due to the formation of cristobalites. As seen in Figure 2, after the FTIR analysis, a small shoulder peak around $3608 \mathrm{~cm}^{-1}$ and a sharp peak around $653 \mathrm{~cm}^{-1}$ were labeled as $\mathrm{Nd}-\mathrm{O}$ vibrations. The presence of a strong peak $\mathrm{O}-\mathrm{H}$ (water) around 3344 and $1639 \mathrm{~cm}^{-1}$ has been shown $[7,8]$. According to the XRD results given in Figure 3, a low crystalline cubic (c) phase $\mathrm{Nd}_{2} \mathrm{O}_{3}$ was observed.

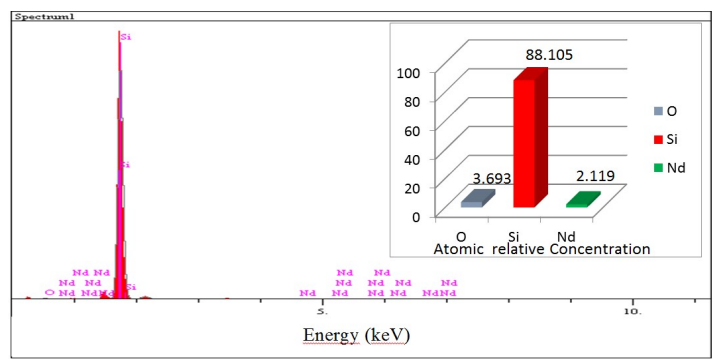

Figure 1. Energy dispersive spectra of $\mathrm{Nd}_{2} \mathrm{O}_{3}$.

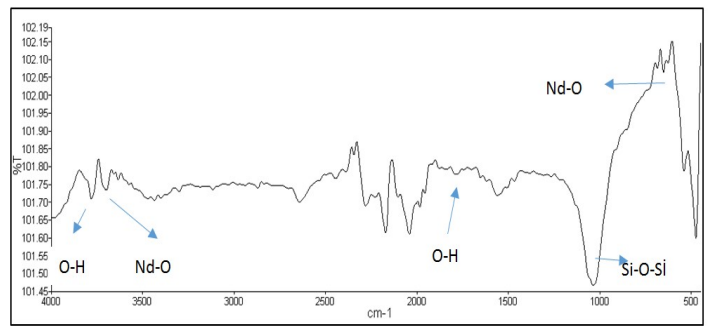

Figure 2. Fourier transform infrared spectroscopy (FTIR) of $\mathrm{Nd}_{2} \mathrm{O}_{3}$ thin films.

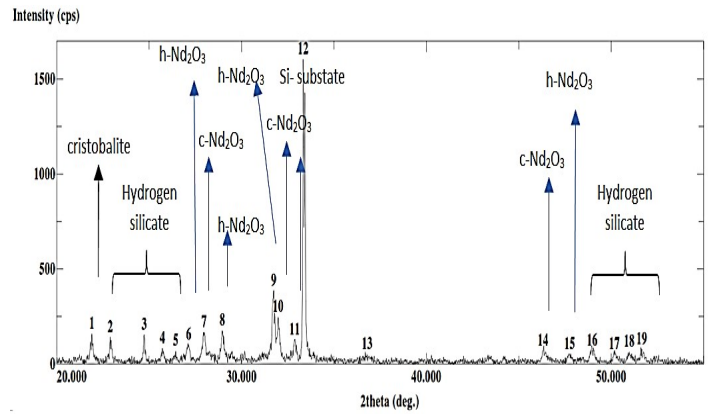

Figure 3. XRD patterns of $\mathrm{Nd}_{2} \mathrm{O}_{3}$ thin films on $\mathrm{Si}-\mathrm{P}(100)$ deposited by the sol-gel dip coating technique.

Due to the traps caused by radiation in the neodymium oxide MOS capacitor structure, the $\mathrm{C}-\mathrm{V}$ curve shifted to the right, as seen in Figure 4. C-V measurements were taken at high frequency to eliminate frequency-dependent charges. The positive charges, which shift the $\mathrm{C}-\mathrm{V}$ curve to the right, are trapped in greater numbers than negative charges. For this reason, the flat band voltage was shifted to the right with radiation dose.

The variation of the flat band voltage calculated from the $\mathrm{C}-\mathrm{V}$ curves is shown in Figure 5 . The flat band voltage shift is relatively linear up to $20 \mathrm{~Gy}$ and reaches saturation at higher doses.

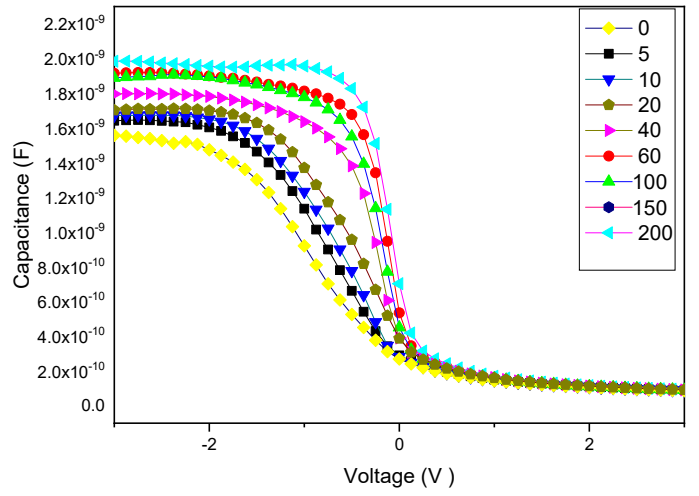

Figure 4. The capacitance-voltage (C-V) curves of the $\mathrm{Nd}_{2} \mathrm{O}_{3} \mathrm{i}-\mathrm{P}(100)$ MOS capacitor for different radiation doses.

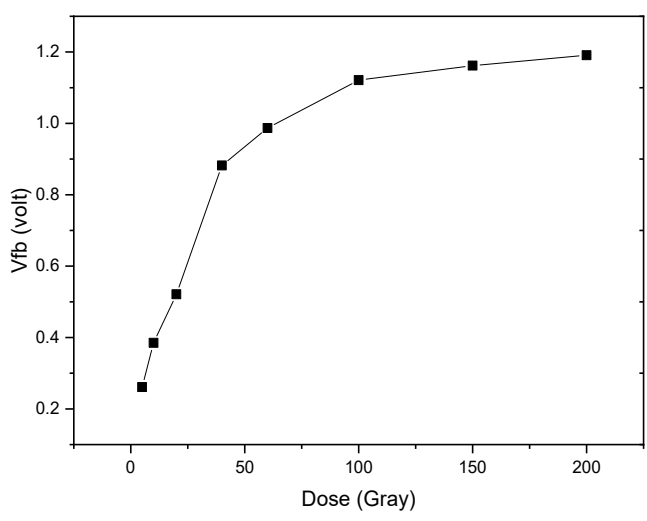

Figure 5. Flat band voltage variation of the $\mathrm{Nd}_{2} \mathrm{O}_{3}$ p-MOS capacitor with total gamma dose.

The evolution of interface states with radiation dose is shown in Figure 6. Density of radiation-induced interface states are calculated from Equation 1 [9]:

$$
\Delta N_{i t}=\frac{C_{o x}\left(\Delta V_{f b}-\Delta V_{m g}\right)}{q A}
$$

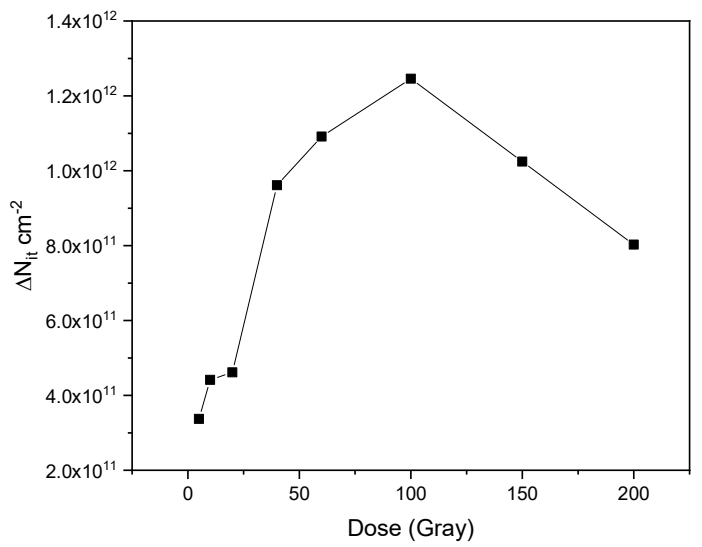

Figure 6. Variation of radiation-induced interface states of the $\mathrm{Nd}_{2} \mathrm{O}_{3}$ p-MOS capacitor with total gamma dose.

The evolution of oxide traps with radiation dose is shown in Figure 7. Density of radiation-induced oxide traps are calculated from Equation 2 [10]: 


$$
\Delta N_{o t}=\frac{C_{o x} \Delta V_{m g}}{q A}
$$

where in Equations (1) and (2), A and $q$ are the capacitor area and the electric charge, respectively, Cox is the oxide capacitance. $\Delta \mathrm{V}_{\mathrm{mg}}$ is the mid-gap voltage shift, and $\Delta \mathrm{V}_{\mathrm{fb}}$ is the flat band voltage shift.

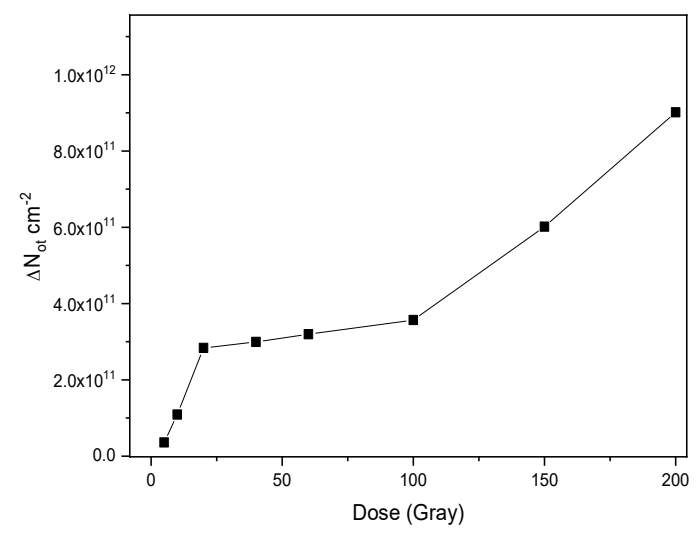

Figure 7. Variation of the radiation-induced oxide traps of the $\mathrm{Nd}_{2} \mathrm{O}_{3}$ p-MOS Capacitor with total gamma dose.

While the radiation-induced interface states increase up to $100 \mathrm{~Gy}$, their density decreases after that. This behavior can be explained by the formation and transformation of interface traps/border traps or by passivation of interface traps at higher radiation doses. Interface states can be of the acceptor and donor type [11]. When donor-like conditions are more dominant, the $\mathrm{C}-\mathrm{V}$ curve shifts to negative values, otherwise to positive values. The oxide traps increase continuously during irradiation.

\section{CONCLUSION}

According to the results of the structural analysis, neodymium oxide structure has been successfully produced. The capacitance-voltage measurement results have illustrated that the curves of the irradiated MOS capacitors shifted to the left with irradiation. It is concluded that neodymium oxide is suitable for electronics applications in radiation measurement.

Acknowledgements: This work was supported in part by Presidency of Turkey, Presidency of Strategy and Budget under Contract Number: 2016K12-2834, in part by Bolu Abant Izzet Baysal University, Bolu, Turkey, under contract BAP. 2014.03.02.764.
REFERENCES

[1] A. Tataroglu, S. Altındal, "Characterization of interface states at $\mathrm{Au} / \mathrm{SnO}_{2} / \mathrm{n}-\mathrm{Si}$ (MOS) structures," Vacuum, vol. 82, no. 11, pp. 1203 - 1207, Jun. 2008. DOI: 10.1016/j.vacuum.2007.12.014

[2] S. Kaya, I. Yildiz, R. Lok, E. Yilmaz, "Co-6o gamma irradiation influences on physical, chemical and electrical characteristics of $\mathrm{HfO}_{2} / \mathrm{Si}$ thin films," Radiat. Phys. Chem., vol. 150, pp. $64-70$, Sep. 2018.

DOI: 10.1016/j.radphyschem.2018.04.023

[3] R. Lok, E. Budak, E. Yilmaz, "Radiation response of zirconium silicate P-MOS capacitor," Microelectron. Reliab., vol. 109, article no. 113663, Jun. 2020.

DOI: $10.1016 /$ j.microrel.2020.113663

[4] A. Kahraman, E. Yilmaz, A. Aktag, S. Kaya, "Evaluation of Radiation Sensor Aspects of $\mathrm{Er}_{2} \mathrm{O}_{3}$ MOS Capacitors under Zero Gate Bias," IEEE Trans. Nucl. Sci., vol. 63, no. 2, pp. 1284 - 1293, Apr. 2016. DOI: $10.1109 /$ TNS.2016.2524625

[5] A. Kahraman, E. Yllmaz, "Ara yüzey seviyelerinin ve seri direncin $\mathrm{Sc}_{2} \mathrm{O}_{3}$ MOS kapasitörünün elektriksel karakteristiği üzerine etkisi," Sakarya Üniversitesi Fen Bilimleri Enstitüsü Dergisi, cilt 22, sayı 3, sayfalar 915 - 921, Haziran 2018. (A. Kahraman, E. Yilmaz, "Effects of interface states and series resistance on the electrical characteristic of $\mathrm{Sc}_{2} \mathrm{O}_{3}$ MOS capacitor," Sak. Univ. J. Sci., vol. 22, no. 3, pp. 915 - 921, Jun. 2018.

DOI: 10.16984 /saufenbilder.327593

[6] A. Kahraman, "Understanding of post deposition annealing and substrate temperature effects on structural and electrical properties of $\mathrm{Gd}_{2} \mathrm{O}_{3}$ MOS capacitor," J. Mater. Sci. Mater. Electron., vol. 29, no. 1, pp. 7993 - 8001, May 2018. DOI: $10.1007 / \mathrm{s} 10854-018-8804-y$

[7] M. Hirose, M. Hiroshima, T. Yasaka, M. Takakura, S. Miyazaki, "Ultra-thin gate oxide growth on hydrogen-terminated silicon surfaces," Microelectron. Eng., vol. 22, no. 1 - 4, pp. 3 - 9, Aug. 1993.

DOI: 10.1016/0167-9317(93)90121-K

[8] G. D. Dhamale, V. L. Mathe, S. V. Bhoraskar, S. N. Sahasrabudhe, S. Ghorui, "Synthesis and characterization of $\mathrm{Nd}_{2} \mathrm{O}_{3}$ nanoparticles in a radiofrequency thermal plasma reactor," Nanotechnology, vol. 27, no. 8, Feb. 2016.

DOI: $10.1088 / 0957-4484 / 27 / 8 / 085603$ PMid: 26808863

[9] R. Lok, S. Kaya, H. Karacali, E. Yilmaz, "The Co-6o gamma-ray irradiation effects on the $\mathrm{Al} / \mathrm{HfSiO}_{4} / \mathrm{p}$ Si/Al MOS capacitors," Radiat. Phys. Chem., vol. 141, pp. 155 - 159, Dec. 2017. DOI: 10.1016/j.radphyschem.2017.06.019

[10] R. Lok, E. Budak, E. Yilmaz, "Radiation response of zirconium silicate P-MOS capacitor," Microelectron. Reliab., vol. 109, article no. 113663, Jun. 2020.

DOI: 10.1016/j.microrel.2020.113663

[11] E. Yilmaz, B. Kaleli, R. Turan, "A systematic study on MOS type radiation sensors," Nucl. Instrum. Methods Phys. Res. Sect. B, vol. 264, no. 2, pp. $287-292$, Nov. 2007.

DOI: 10.1016/j.nimb.2007.08.081 